\title{
Behind the Scenes: COVID-19 Consequences on Broadcast Sports Production
}

\author{
Roxane Coche and Benjamin J. Lynn \\ University of Florida
}

\begin{abstract}
Live events are central to television production. Live sporting events, in particular, reliably draw big audiences, even though more consumers unsubscribe from cable to stream content on-demand. Traditionally, the mediated production of these sporting events have used technical and production crews working together onsite at the event. But technological advances have created a new production model, allowing the production crew to cover the event from a broadcast production hub, miles away, while the technical crew still works from the event itself. These remote integration model productions have been implemented around the world and across all forms of sports broadcasting, following a push for economic efficiency-fundamental in a capitalist system. This manuscript is a commentary on the effects of the COVID-19 global crisis on sports productions, with a focus on remote integration model productions. More specifically, the authors argue that the number of remote sports productions will grow exponentially faster, due to the pandemic, than they would have under normal economic circumstances. The consequences on sport media education and research are further discussed, and a call for much needed practice-based sports production research is made.
\end{abstract}

Keywords: education, live sports, REMI

NASCAR (the National Association for Stock Car Auto Racing) returned to racing in Darlington, South Carolina, on May 17, 2020, more than 2 months after the last pre-COVID-19 event, on March 8. With no fans allowed at Darlington Raceway, the only way to follow the action live was to watch it on Fox Sports. But the absence of fans was not the only notable consequence of the pandemic. While introducing the event, announcer Mike Joy explained that only camera operators, a technical director, and a director were on site in Darlington. The producers and announcers worked from a studio in Charlotte, North Carolina, and the graphics and replay operators were at the Fox Network Center in Los Angeles. In 1 min, Joy essentially described the REMote Integration (REMI) production model to his

The authors are with the Dept. of Telecommunication, University of Florida, Gainesville, FL, USA. Coche (rcoche@ufl.edu) is corresponding author. 
audience. This scene is early evidence of what we argue in this essay: the COVID19 pandemic will change the broadcast industry, especially the sports production field, quickly and for good.

\section{Live Sports Productions}

Live events are central to television production. Live sporting events, in particular, reliably draw big audiences. Television production techniques for these events have evolved and been refined for more than half a century, but the drastic changes COVID-19 brought to the world are revolutionalizing the sports broadcast industry. Television sports productions have traditionally used technical and production crews working together on-site at the event. Technical crews, consisting of mostly camera operators; audio, video, and electrical engineers (who ensure all the truck equipment is functioning as it should); utilities (who pull cables into position); and a technical manager, worked in the venue and the mobile production trucks to set up and maintain the gear necessary to shoot the action. Working in the same mobile production trucks and venues, the production crews were led by a producer and director, and included a team of announcers, graphics personnel, color analysts, and statisticians. Together, the technical and production crews produced the content that aired on television entirely from the event location (see Figure 1).

Though having both technical and production crews on-site has remained the traditional setup for sports productions throughout the years, networks have been trying to change it for more than 2 decades, primarily to save money. In 1996, NBC Sports decided to take advantage of the Olympic games' relative proximity to their

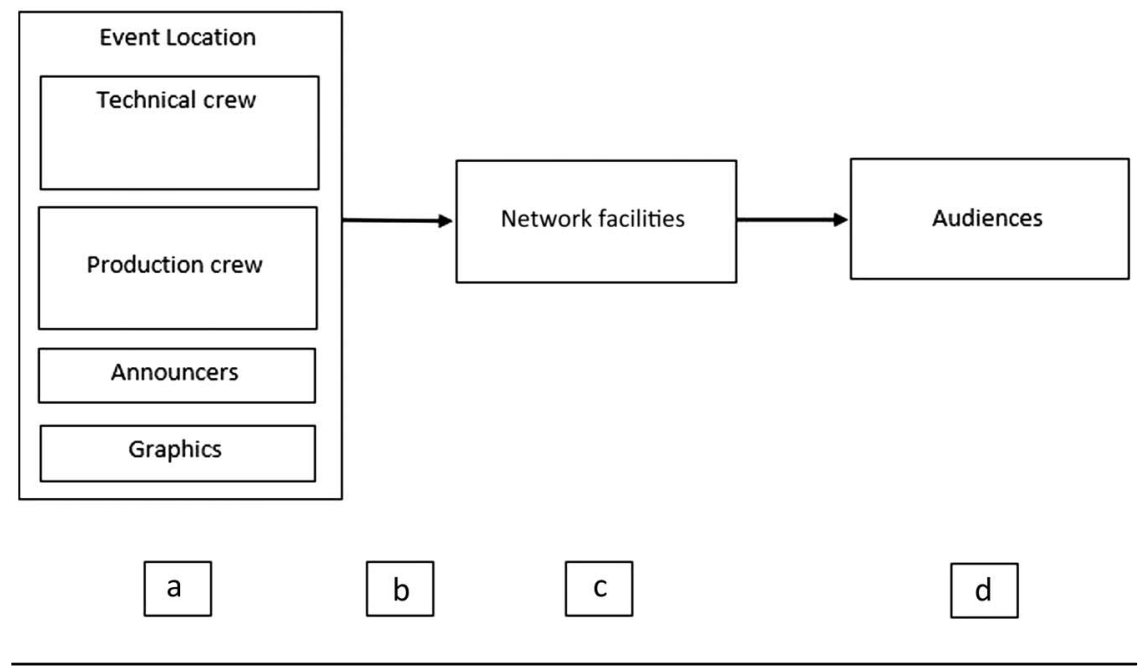

Figure 1 - Signal flow in the traditional mobile sports production workflow. With technical and production crews on-site together, the content is captured and packaged (a), then sent to the network facilities via satellite (b). The networks insert final graphics (c) and pass the signal on for mass distribution (d). 
headquarters at Rockefeller Center in New York to premier their new digital equipment infrastructure during the 1996 Atlanta Summer Olympic Games (DeFilippis, 2017). With technological advances since, a new production model called REMI was born. Through it, the technical crew is still required to be on-site, but the production crew can work from "home," meaning a broadcast production hub that can be located virtually anywhere in the world or, in some cases, from a person's literal home (Dachman, 2020; see Figure 2). As such, in the words of Fox Sports' Senior Vice President of Technical and Field Operations Mike Davies, REMIs constitute

A paradigm shift, but the workflow stays exactly the same. You still have a producer and a director. You still have you still have some technicians just like if you had at, say an MLS game, and typically you'd send out just 30 people, between locals and travelers or production personnel. Now you still probably have those same 30 people, it's just half of them are back in the studio doing these shows. (Lynn, Davies, Green, \& Stum, 2019)

The REMIs have been introduced around the world (Bickerton, 2019; DeFilippis, 2017; Kerschbaumer, 2019; Lurye, 2018) and across all forms of sports broadcasting over the years, but their propagation has been slow, mostly because of financial factors and human habits. But the COVID-19 crisis is fast-tracking the inevitable REMI implementation process.

\section{Financial Factors}

When networks began trying to change the traditional production model, they did so mainly for financial reasons. While the traditional production model was highly

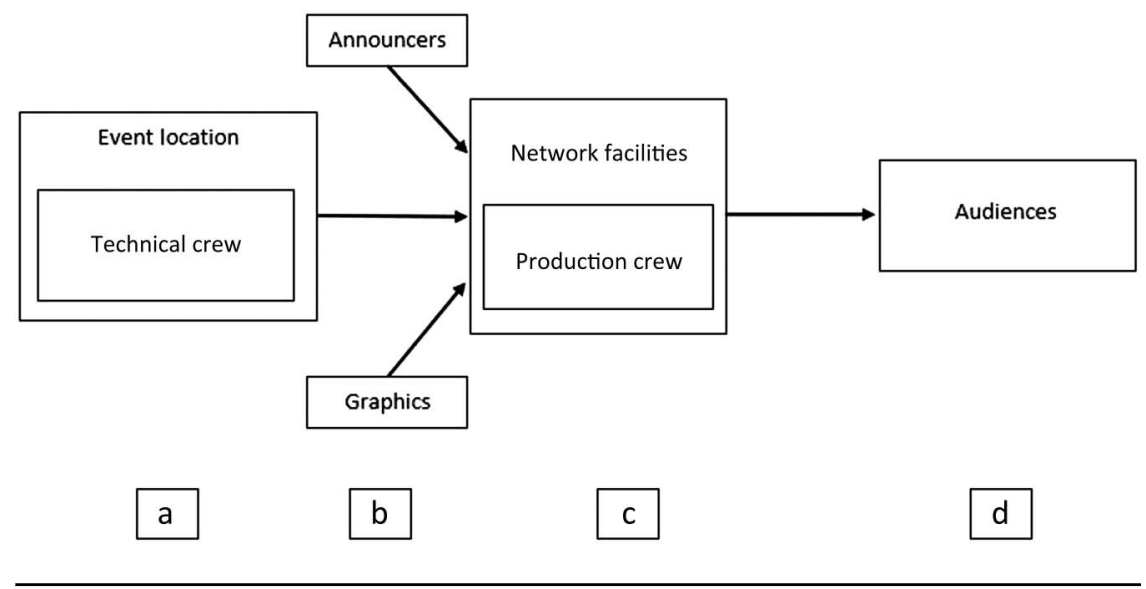

Figure 2 - Signal flow in the REMI (REMote Integration) sports production workflow. The technical crew is on-site at the event, sending signals back to the network facilities (a). Announcers and other personnel may be at home, sending additional signals to the network facilities (b). The production crew, now located in the network facilities (c), combines the incoming signals to create a finished product that is passed on for mass distribution (d). 
effective at producing structurally sound broadcast sports productions, it came with high costs at a time when broadcast rights fees were climbing to astronomical new heights (Ourand, 2018). Because both the sports and the media industries are grounded in a global capitalist system, economic efficiency is constantly sought out in sports productions. So, the desire to do more for less prompted networks to find new, less-expensive ways to cover live sporting events, which resulted in the creation of remote productions. "Instead of sending a handful of people out to work in a truck in a compound," NASCAR Productions' Steve Stum explained, "we sent half a dozen signals back to Charlotte. And that's how we started with it, and then small shows and it got a little bit bigger and bigger" (Lynn et al., 2019). Indeed, having both the technical and production crew travel across a country or around the world to events came with a hefty price tag. Stum said it was a third of his organization's production budget, a sum of money that could be better invested in the show itself to make "the product that much better" (Lynn et al., 2019).

In addition to the crews traveling, the production equipment transited between events, which translated to financial inefficiency. As previously explained, productions were built in a truck (i.e., a mobile entity), which traveled, too. While in transit, the trucks' resources were unavailable, and thousands of miles on the road every month, all year long, meant a lot of downtime for the equipment. With the new REMI model, the cameras, microphones, and cables are still traveling with the technical crew, but the actual control room, including graphics and replay machines, is staying put in one or more broadcast production hub(s), where production crews can work day in and day out, year-round. A centralized production hub could be used for a soccer game in Paris, a basketball game in Memphis, and a football game in California on the same day.

\section{Adversity in REMI Adoptions}

With so many apparent advantages, it is reasonable to question why the REMI model was not adopted as soon as it was introduced. There were three main reasons: (a) technical limitations associated with the communication channels had to be overcome; (b) broadcast production hubs had to be built, which is an expensive and time-consuming process; and (c) change does not come easily for human beings, let alone a whole industry, as discussed below.

The first obstacle to overcome was a communication challenge: slight delays in the internal audio and video created a less-than-ideal product. Early REMI productions were riddled with camera mistakes that were unacceptable in traditional sports broadcasts. Communication delays caused camera shots to be used as the cameras made high-speed movements, which broadcasters found distracting. Furthermore, camera operators struggled to follow the action because of delays in their on-air video signals, known as "return video." As Steve Stum explained,

We found out really early on was the communication between the director and producer and the camera guys on site is critical. Return video back to the camera guys who are running return video, if it's not there within milliseconds, a half a second, it kills it. (Lynn et al., 2019) 
What may have seemed like small inconsistencies to average viewers were perceived as major disruptions to the visual structure of the broadcast, so it created resistance to the model within the professional industry. Technological advances helped improve the situation until the delays were past the threshold of substantially influencing the quality of the product and directors became better at adjusting their technique to work within the constraints of the technology.

The second issue delaying the implementation of the REMI model was associated with the infrastructure required by the model. Building a centralized production hub at the network level requires studio space, tens of millions of dollars in real estate, furniture and equipment, and time for the planning and installation process. This obstacle has since been resolved in the United States, as most major networks have at least one production hub built and ready for use. Disney's networks, ESPN and ABC, have had theirs operational for a few years in Bristol, Connecticut; Charlotte, North Carolina; and Orlando, Florida. FOX Sports' main hub is in Los Angeles, and NBC has deployed remote solutions alongside the GOLF Channel. With the technical infrastructure in place, the REMI model faced only human nature to be employed at scale. And that nature is a powerful force, as diffusion of innovations theory (Rogers, 1962) has shown, but it can be overturned through extraordinary circumstances, like a pandemic.

\section{Human Habits}

The REMI implementations have also remained slow because of the sports broadcast industry's sets of practices, traditions, and rules, which have led its actors (the crew members and announcers) and its audience to have certain behaviors and expectations. Large-scale change is never easy. Actually, "most organization change is not significant or successful. Organizational improvements do occur, even frequently, and do work, but large-scale, fundamental organization change that works is rare" (Burke, 2017, p. 9). Human beings are creatures of habit: we get comfortable in what we know. As a result, we often experience change aversion (a state of anxiety or at least discomfort) when something unfamiliar replaces something familiar. In 1962, Rogers introduced the diffusion of innovation theory, which hypothesizes that people adopt an innovation (a new behavior or product, for instance) gradually, following a bellshaped curve: only $2.5 \%$ of people will risk trying an innovation at first, and another $13.5 \%$ will follow before the rest of the population is, slowly, even willing to give it a shot. A few years later, Prochaska and DiClemente (1983) developed the stages of change model, positing that change is a six-step process, which is cyclical rather than linear and, thus, can include one or several relapses. In other words, change takes time and is hard. Because that statement is true for one person, it is even more so when many are involved. Sometimes, people fight change because they have worked hard toward acquiring certain skills and are unwilling to start from scratch. When sports productions moved to REMIs and new communication delays greatly affected the quality of a broadcast, professional broadcasters got frustrated because their work suffered from major changes they had never wished for in the first place. Broadcast management 
sentiment clearly mirrored that found in other industry sectors, which believed that adopting a remote work model was too much of a risk. But the novel coronavirus redefined risk levels around the world (Mattioli, 2020).

\section{COVID-19 Consequences}

The COVID-19 pandemic redistributed the cards: change was forced onto virtually everyone around the world, and sports have been particularly affected by the absence of live events, which lasted for several months in many countries around the world. From an economic perspective, the pandemic has put many sports broadcast professionals out of work-at least temporarily until live competitions returned. The cancelation or postponement of annual domestic championships and major international events, including the Olympics, affected the lives of thousands of workers in sports broadcasting. For these people, going back to work when sports returned provided some comforting familiarity, even if the work environment has changed from what it was before COVID-19 happened.

From the perspective of the audience, sports networks aired old games, many filmed before high-definition technology was invented, along with new content that includes subquality footage shot by amateurs and/or recorded webcam videos, which often lags. For example, ESPN's HORSE tournament, a basketball shooting competition for charity, was intensely criticized for "laughably poor video quality" (Joseph, 2020, para. 5) and "muffled and incoherent" sound (Casselberry, 2020, para. 4). After such experiences, productions of live sports will look remarkably better than what aired during the pandemic. Before COVID-19, switching to a REMI model presented financial advantages, but unknown risks that television executives were unwilling to take because they could not afford to alienate their audience. Though the risks have technically not changed, they are now perceived as minimal compared with the colossal challenges COVID-19 brought upon the industry. In other words, communication delays may still lower production quality some, but the transition will seem insignificant. Indeed, with poor production standards still salient on audience members' minds, someone who might have complained about picture quality before the COVID-19 crisis will be less likely to do so post-COVID-19 because their expectations will have naturally lowered-at least ever so slightly. So, the pandemic has essentially provided sports media executives with a free pass to move the model forward with little to no concerns about quality-related complaints from the audience.

The number of remote sports productions was inevitably going to increase because of the model's cost efficiency, but the COVID-19 pandemic has armed sports media executives with other benefits to accelerate their implementation. Besides readjusting people's expectations, COVID-19 has introduced the concept of social distancing into our societies. This concept makes it effectively impossible to continue traditional sports productions, which require a dozen or so people to work side by side in a small remote truck for hours at a time. The conditions in a remote production truck are similar to those found on a commercial airline, where passengers seated around an infected person have an 80-100\% chance of becoming infected too (McKeever, 2020). In other words, production trucks are an ideal environment for COVID-19 to spread. 
Conversely, not only are the recently built broadcast production hubs (for REMI productions) much larger than the trucks, but the model is also scalable, which means that if a single control room is too small for the entire crew, it can be integrated with one or multiple other control rooms to ensure that crew members maintain the necessary physical distance between one another. With social distancing a requirement, media management can justify moving to a REMI model to keep crews safe, and labor unions will have no alternative but to acquiesce.

Accordingly, the financial and human challenges that dampened the proliferation of REMI productions have mostly subsided because the COVID-19 pandemic has turned both the sports and the media worlds upside down. But social distancing is the one element that will unequivocally move every network to deploy a REMI model as soon as sporting events resume. And once the model is deployed at scale, networks are unlikely go back to the more expensive traditional broadcast model, even if a vaccine for COVID-19 is found (Dachman, 2020). Instead, networks will prefer to extend the REMI model beyond the production crew. Talent (hosts, announcers, etc.) may not travel on site either when sports return, because announcers should not share small, enclosed booths in a stadium or arena, and REMI developments allow them to safely work from a larger centralized production hub or a studio setup in their own home.

\section{Meanings for Scholars and Educators}

The expected surge of REMI productions will revolutionize the sports broadcast industry. While one cannot anticipate every possible consequence, we can make informed predictions about what educators and scholars should expect moving forward.

\section{Effects on Education}

Though we, the authors, have taught at only a handful of institutions in North America, we have come across hundreds of students whose motivations to pursue a career in sports broadcast include traveling from stadium to stadium and city to city. The allure of being on-site to witness the greatest sporting moments is a major draw to the broadcast industry. With the REMI model, production crews will no longer travel and, as previously mentioned, talent will likely travel much less, if at all. So, students' expectations must be adjusted from the first day of class. The main risk of doing so relates to the attractiveness of our field: will working as a sports broadcaster remain as interesting to young people if they find out they will work in a dark room and talk about what they see unfold on screens? Though crews working in a production truck were already in a similar situation, they still benefited from the sport stadium atmosphere before and after their work hours. They still felt like they were a part of the pomp and prestige that is sport. Working from the same broadcast hub day after day takes that away from them.

Another major concern is skill development, especially for talent. How will we, as educators, develop talent if students do not have the opportunity to spend 
significant time around the sport they are covering and the atmosphere it creates? Up until now, announcers have often attended team practices and interviewed coaches and players to obtain some inside information to use in their on-air comments. Those deeper insights will be gone if the talent stays home. How will that affect the audience? The current cohort of announcers have all had experience in the field, so the real test would be when the next generation of studio-only talent starts to take over.

Skill development must also be adjusted for behind-the-camera crews. Broadcast programs in the United States have invested in mobile production trucks these past few years. Some have even signed agreements with online networks to have some or all of their institution's athletic events streamed live through the work of all-student crews. While such investments are still useful because the equipment in a truck remains similar to that of a production hub's, acquiring a production truck should not be a priority for any program. Regardless of the model students are learning with (truck or immobile control room), institutions must incorporate remote workflows with communication delays, or they will put their students at a severe disadvantage.

\section{Repercussions on Research}

The paradigm shift in broadcast sports productions presents communication scholars with new research opportunities. Indeed, the production changes proposed by the networks are like an experiment on a scale previously unimaginable to scholars. From FOX Sports' decision to insert manufactured crowd noise and use computer-generated imagery to add fans in the stands of their NFL football games (Evans, 2020) to most networks radically downsizing productions in an effort to minimize crews' exposure to the virus, scholars have opportunities to explore the effects of such changes on audiences and society, particularly as audiences transition following an exceptional massive gap in live sports coverage.

The pandemic has also created a unique chance to explore the diffusion of innovations theory in catastrophic conditions, which is important for crisis management in our field, especially as some expect pandemics to become more common (Whiting, 2020). Adoption of the REMI model appeared to be following a normal diffusion curve prior to the pandemic, with some broadcasters being innovators or early adopters as we slowly moved into the majority switching to the model. The pandemic accelerated the diffusion curve such that, in just a couple of months, every broadcaster has adopted the REMI model. Research in this area could help predict and guide responses to future pandemics and crisis situations that affect sport media, which could significantly impact mass communication research. Yet, developing or advancing theory should not be the sole target of this new line of research. Communication and mass communication journals, including those specialized in sports, put considerable focus on theory, often at the expense of practice, when both are complementary. Practical studies are discarded by reviewers as mere reports that have no space in academic journals. Theory is important. Without it, practice lingers, with little to no potential for improvement. But without practice, theory remains abstract and useless in the real world. Advancing theory is an outspoken mission of the majority of the academic journals in (mass) communication and sports, and it should be because it is vital to a healthy 
scholarly field. However, doing so at the expense of practical research that can be immediately useful to the industry only widens the gap between academia/ scholarly activity and the mass communication industry, which many scholars claim to want to eliminate.

Sports broadcasters will face monumental communication and production challenges once sports return; challenges that academics can and should help overcome with theoretically grounded solutions. This is an opportunity for scholars to take the wealth of knowledge they have accumulated through decades of research and help guide production practices for the betterment of society. We know sports are important to society, so we have a social obligation to assist broadcasters in reshaping sports productions after the pandemic. While the process will be difficult, as any large-scale shifts would be, working with broadcasters now may give scholars an opportunity to move other ideas forward in the future.

The COVID-19 pandemic has uprooted our world as a whole, and its consequences on the sports broadcast industry in particular will be far-reaching and remain forever. As we seek to better understand the pandemic's effects on the industry, practice-based sports production research should be conducted as soon as possible and across various markets.

\section{Conclusion}

Broadcast sports productions are going through drastic changes because of the COVID-19 pandemic. The reshaping of an industry that is so vital to the health of sports communication will require educators to adjust how they prepare students for integration into the field and offers two key opportunities to researchers. First, scholars can apply decades of accumulated mass communication knowledge to help broadcasters overcome complex pandemic-caused production challenges. The methods used to communicate sports to mass audiences through broadcasting have evolved over more than half a century to become the main reason people keep cable subscriptions today. But these refined methods are no longer safe to be used. Saunders (2020), who reviewed NASCAR's returning race in Darlington, South Carolina, observed,

The commentators did a good job with what they had, but at points, as with any motor race, the coverage felt as if it needed an injection of energy that a long train of race cars simply can't inject on a lap-by-lap basis. (para. 10)

This is initial evidence that broadcasters need to experiment with new techniques as live sports competitions resume, and scholars are trained to help with such a mission. Rather than waiting for sports broadcasts to return to analyze their effects in a reactive approach, accumulating more knowledge that seldom spreads past academic journals, scholars should work with broadcasters proactively to explore how to best bring sports broadcasts back safely and effectively. Second, the pandemic presents scholars with an opportunity to test mass communication theories on a scale that was unimaginable prior to COVID-19 and may never present itself again. The time is now for scholars to turn their attention to the changes happening in broadcast sports productions. 


\section{References}

Bickerton, J. (2019, July 1). Eurosport to build centralised content hubs across Europe. Sport Broadcast. Retrieved from https://www.broadcastnow.co.uk/production/eurosport-tobuild-centralised-content-hubs-across-europe/5140647.article

Burke, W.W. (2017). Organization change: Theory and practice (5th ed.). Thousand Oaks, CA: Sage.

Casselberry, I. (2020, April 13). ESPN's NBA HORSE challenge misses badly with blurry video, muffled sound, no creativity. Awful Announcing. Retrieved from https://awfulannouncing. com/espn/espn-nba-horse-challenge-bad-miss-blurry-video-no-creativity.html

Dachman, J. (2020, May 13). From the jump to Korean baseball, ESPN's 'live from home' efforts keep the content factory churning. Sports Video Group. Retrieved from https:// www.sportsvideo.org/2020/05/13/from-the-jump-to-korean-baseball-espns-live-fromhome-efforts-keep-the-content-factory-churning/

DeFilippis, J. (2017). Take me out to the ballpark ... NOT. TVTechnology. Retrieved from https://www.tvtechnology.com/news/take-me-out-to-the-ballparknot

Evans, J. (2020, May 13). Joe Buck: If NFL games don't have spectators, Fox might add CGI fans, crowd noise to broadcasts. USA Today. Retrieved from https://www.usatoday. com/story/sports/nfl/2020/05/13/joe-buck-fox-possibilities-nfl-games-without-fanscoronavirus $/ 5188573002 /$

Joseph, A. (2020, April 12). NBA fans quickly realized that the HORSE Challenge was just terrible TV. For The Win. Retrieved from https://ftw.usatoday.com/2020/04/nbahorse-challenge-reaction-jokes-terrible-tv-quality-espn

Kerschbaumer, K. (2019, May 15). IAAF World relays in Japan are produced out of NEP Andrews hub in Sydney. Sports Video Group News. Retrieved from https://www. sportsvideo.org/2019/05/15/iaaf-world-relays-in-japan-produced-out-of-nep-andrewshub-in-sydney/

Lurye, R. (2018, February 23). To NBC, Stamford may as well be an olympic village. Hartford Courant. Retrieved from https://www.courant.com/business/hc-bizstamford-nbc-sports-olympics-20180223-story.html

Lynn, B., Davies, M., Green, A., \& Stum, S. (2019). Remote sports productions: Equipping educators for the future of television sports broadcasting. Panel discussion presented at the 2019 Broadcast Education Association Annual Convention, Las Vegas, Nevada.

Mattioli, D. (2020, May 16). When it's time to go back to the office, will it still be there? Wall Street Journal. Retrieved from https://www.wsj.com/articles/when-its-time-togo-back-to-the-office-will-it-still-be-there-11589601618?mod=hp_lista_pos1

McKeever, A. (2020, March 6). Here's how coronavirus spreads on a plane- and the safest place to sit. National Geographic. Retrieved from https://www.nationalgeographic. com/science/2020/01/how-coronavirus-spreads-on-a-plane/\#close

Ourand, J. (2018, May 3). The escalation of sports-rights fees can be traced to a 2008 ESPN deal. Bizjournals. Retrieved from https://www.bizjournals.com/newyork/news/2018/ 05/03/escalation-of-sports-rights-fees-traced-to-espn.html

Prochaska, J.O., \& DiClemente, C.C (1983). Stages and processes of self-change of smoking: Toward an integrative model of change. Journal of Consulting and Clinical Psychology, 51(3), 390-395.

Rogers, E.M. (1982). Diffusion of innovations New York, NY: Free Press.

Saunders, N. (2020, May 18). Some lessons for F1 from NASCAR's return. ESPN. Retrieved from https://www.espn.com/f1/story/_id/29189095/some-lessons-f1-nascar-return

Whiting, K. (2020). Coronavirus isn't an outlier, it's part of our interconnected viral age. World Economic Forum. Retrieved from https://www.weforum.org/agenda/2020/03/ coronavirus-global-epidemics-health-pandemic-covid-19/ 